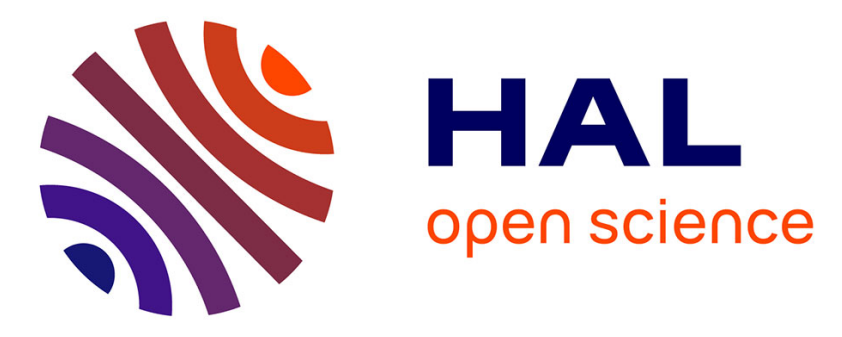

\title{
5-(3,4-Dimethoxybenzyl)-7-isopropyl-1,3,5-triazepane- 2,6-dione acetonitrile solvate refined using a multipolar atom model
}

Krzysztof Ejsmont, Joel Boeglin, Claude Didierjean, Gilles Guichard, Christian Jelsch

\section{To cite this version:}

Krzysztof Ejsmont, Joel Boeglin, Claude Didierjean, Gilles Guichard, Christian Jelsch. 5-(3,4Dimethoxybenzyl)-7-isopropyl-1,3,5-triazepane-2,6-dione acetonitrile solvate refined using a multipolar atom model. Acta Crystallographica Section C : Crystal Structure Communications [1968-2013], 2010, 66 (6), pp.o292-o294. 10.1107/S0108270110016331 . hal-01713017

\section{HAL Id: hal-01713017 \\ https://hal.science/hal-01713017}

Submitted on 20 Feb 2018

HAL is a multi-disciplinary open access archive for the deposit and dissemination of scientific research documents, whether they are published or not. The documents may come from teaching and research institutions in France or abroad, or from public or private research centers.
L'archive ouverte pluridisciplinaire HAL, est destinée au dépôt et à la diffusion de documents scientifiques de niveau recherche, publiés ou non, émanant des établissements d'enseignement et de recherche français ou étrangers, des laboratoires publics ou privés. 


\section{5-(3,4-Dimethoxybenzyl)-7-isopropyl-1,3,5-triazepane-2,6- dione acetonitrile solvate refined using a multipolar atom model}

\section{Krzysztof Ejsmont, Joel Boeglin, Claude Didierjean, Gilles Guichard and Christian Jelsch}

Acta Cryst. (2010). C66, o292-0294

Copyright (C) International Union of Crystallography

Author(s) of this paper may load this reprint on their own web site or institutional repository provided that this cover page is retained. Republication of this article or its storage in electronic databases other than as specified above is not permitted without prior permission in writing from the IUCr.

For further information see http://journals.iucr.org/services/authorrights.html

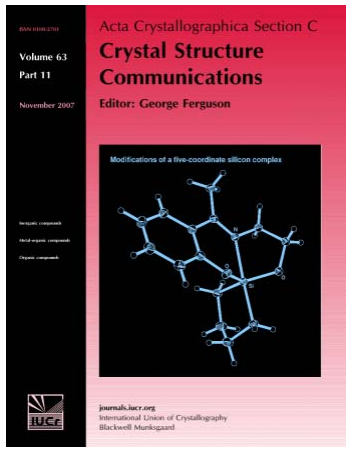

Acta Crystallographica Section C: Crystal Structure Communications specializes in the rapid dissemination of high-quality studies of crystal and molecular structures of interest in fields such as chemistry, biochemistry, mineralogy, pharmacology, physics and materials science. The numerical and text descriptions of each structure are submitted to the journal electronically as a Crystallographic Information File (CIF) and are checked and typeset automatically prior to peer review. The journal is well known for its high standards of structural reliability and presentation. Section $C$ publishes approximately 1000 structures per year; readers have access to an archive that includes high-quality structural data for over 10000 compounds.

Crystallography Journals Online is available from journals.iucr.org 
Acta Crystallographica Section C

Crystal Structure

Communications

ISSN 0108-2701

\section{5-(3,4-Dimethoxybenzyl)-7-isopropyl- 1,3,5-triazepane-2,6-dione aceto- nitrile solvate refined using a multi- polar atom model}

\section{Krzysztof Ejsmont, ${ }^{\text {a Joel Boeglin, }}{ }^{\text {b }}$ Claude Didierjean, ${ }^{\text {c }}$ Gilles Guichard ${ }^{\mathrm{d}}$ and Christian Jelsch ${ }^{\mathrm{c} *}$}

${ }^{\text {a }}$ Faculty of Chemistry, University of Opole, Oleska 48, 45-052 Opole, Poland, ${ }^{\mathbf{b}} \mathrm{CNRS}$, Laboratoire d'Immunologie et Chimie Thérapeutiques, Institut de Biologie Moléculaire et Cellulaire, 15 rue Descartes, 67000 Strasbourg, France, ${ }^{\mathbf{c} C N R S ~ U M R}$ $7036\left(\mathrm{CRM}^{2}\right)$, Laboratoire de Cristallographie, Résonance Magnétique et Modélisations, Faculté des Sciences et Techniques - UHP, BP 70239, 54506 Vandoeuvre-lès-Nancy Cedex, France, and ${ }^{\mathbf{d}}$ Institut Européen de Chimie et Biologie, Université de Bordeaux - CNRS UMR 5248 CBMN, 2 rue R. Escarpit, 33607 Pessac Cedex, France

Correspondence e-mail: christian.jelsch@crm2.uhp-nancy.fr

Received 23 March 2010

Accepted 4 May 2010

Online 12 May 2010

The crystal structure of the title compound, $\mathrm{C}_{16} \mathrm{H}_{23} \mathrm{~N}_{3} \mathrm{O}_{4} \cdot-$ $\mathrm{CH}_{3} \mathrm{CN}$, was refined using a multipolar atom model transferred from an experimental electron-density database. The refinement showed some improvement in crystallographic statistical indices compared with the independent atom model. The triazepane ring adopts a twist-boat conformation. In the crystal structure, the molecule forms intermolecular contacts with 14 different neighbours. There are two $\mathrm{N}-\mathrm{H} \cdots \mathrm{O}$ and one $\mathrm{C}-\mathrm{H} \cdots \mathrm{O}$ intermolecular hydrogen bond.

\section{Comment}

1,3,5-Triazepane-2,6-diones are a novel class of dipeptidomimetics (Lena et al. 2006; Lena \& Guichard, 2008) whose skeleton can be readily prepared starting from $\mathrm{N}$-protected dipeptides. All five points of diversity can be manipulated using either solution-phase or solid-phase synthesis. Our interest in 1,3,5-triazepane-2,6-diones stems from the identification of several inhibitors of group $\mathrm{V}$ and $\mathrm{X}$ of secreted phospholipase A2 (Muller et al., 2006). With the aim of improving the potency of the first reported inhibitors, we have started structure-activity relationship studies by systematically varying the nature of the substituents on the ring, and at the amide $\mathrm{N} 3$ position in particular. Interestingly, the nature and the number of substitutents on the ring can dramatically affect the overall geometry, with the side chain at C7 adopting a pseudo-equatorial or pseudo-axial orientation. Moreover, 1,3,5-triazepane-2,6-diones can be used in crystal engineering to create helical molecular tapes that can self-assemble to form channel-type structures (Schaffner et al., 2006). We report here the structure of the title compound, (I), an analogue of cyclo(L-Val-gSar-CO) (Aubert et al., 2007) in which the methyl group at N3 is replaced by the much bulkier 3,4-dimethoxybenzyl group. This structure has been refined using a multipolar atom model.

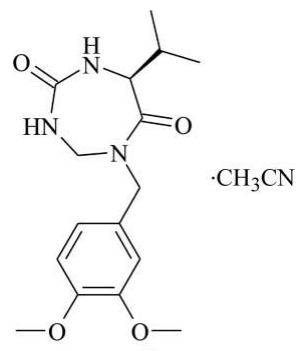

(I)

Initially, in the independent atom model (IAM) refinement, a conventional spherical neutral atom model was applied. Scale factors, atomic positions and displacement parameters for all atoms were refined using the MoPro program (Guillot et al., 2001; Jelsch et al., 2005) until convergence. In the experimental library multipolar atom model (ELMAM; Pichon-Pesme et al., 2004; Zarychta et al., 2007) refinement, the same parameters were varied but a multipolar charged atom model was applied. The electron-density parameters were transferred from the ELMAM library and subsequently kept fixed. Riding constraints on $\mathrm{H}$-atom isotropic displacement parameters were applied similarly in both refinements, which were carried out with the same diffraction data using all reflections.

The ELMAM refinement shows a slight improvement in statistical indexes when compared with the IAM refinement. The $I>2 \sigma(I)$ crystallographic factors are reduced from 5.18 to $3.59 \%$ for $R(F)$ and from 3.86 to $2.53 \%$ for $w R_{2}(F)$. The minimum and maximum peaks in the residual electron density

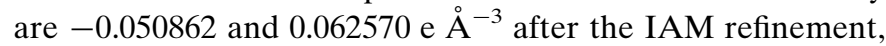

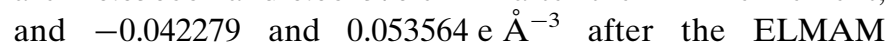
refinement. The largest effect of the multipole transfer on the crystallographic structure is observed on the atomic displacements. The average value of $U_{\text {eq }}$ (geometric mean of eigenvalues $U_{i}$ ) derived from the IAM refinement is $0.0214 \AA^{2}$, which is slightly higher than the value of $0.0182 \AA^{2}$ from the ELMAM refinement. With the IAM spherical atom model, the displacement parameters are incorrect as they incorporate some significant deformation electron density, due to improper deconvolution between these two features (Jelsch et al., 1998).

The molecular structure of (I), with the atomic numbering scheme, is presented in Fig. 1. All bond distances and angles are normal (Table 1) and are in good agreement with the geometry of similar 1,3,5-triazepane-2,6-diones (Lena et al., 2006; Lena \& Guichard, 2008). The $S$ configuration of the C atom at the 2-position of the seven-membered ring was assumed from the precursor Boc-L-Tic OH compound. The triazepane ring adopts a twist-boat conformation, TB (Boessenkool \& Boyens, 1980), similar to those observed in the crystal structures of carbazepine (Hempel et al., 2005; Lisgarten et al., 1989). The seven-membered ring consists of 


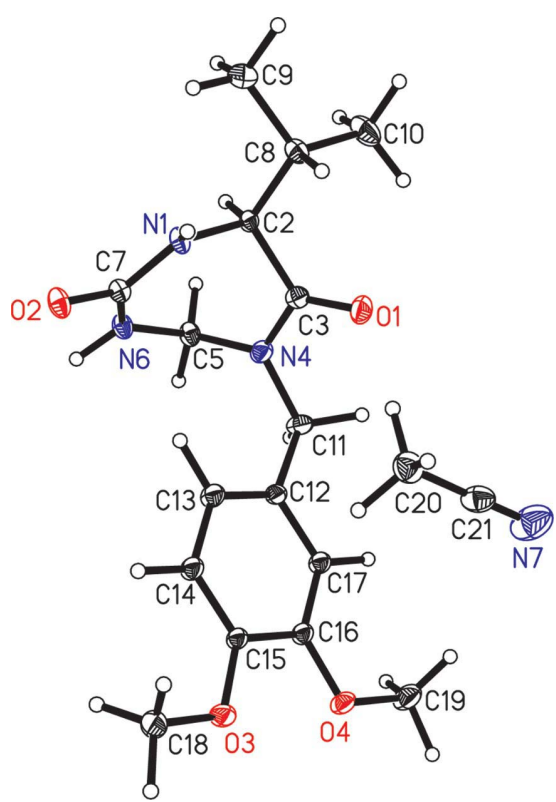

Figure 1

The molecular structure of (I), showing the atom-labelling scheme. Displacement ellipsoids are drawn at $50 \%$ probability level and $\mathrm{H}$ atoms are shown as small spheres of arbitrary radii.

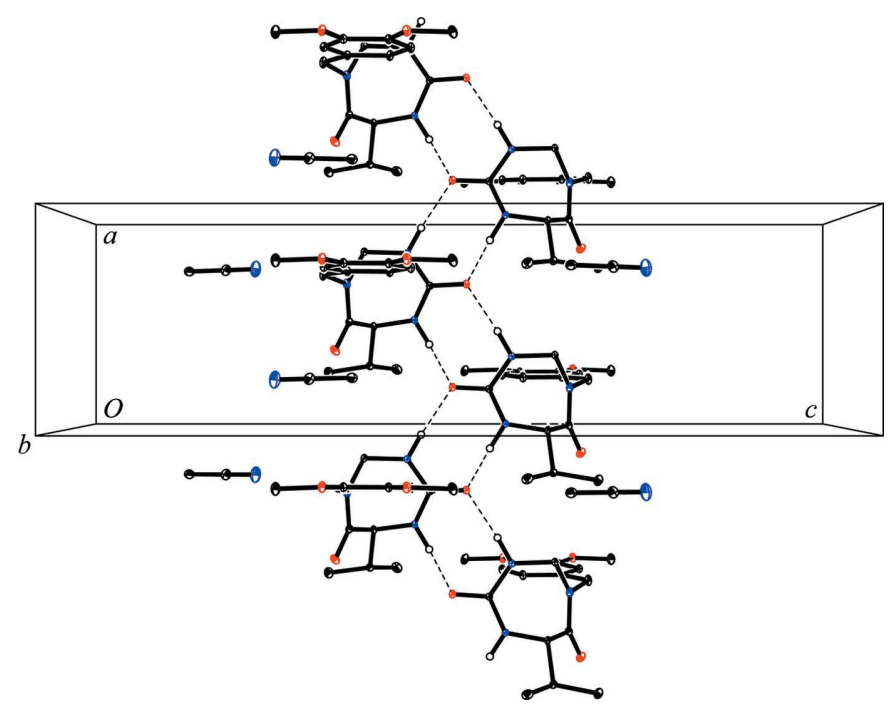

Figure 2

A packing diagram for (I). Dashed lines indicate hydrogen bonds.

two nearly planar halves. The first is defined by atoms $\mathrm{C} 2 / \mathrm{C} 3 /$ $\mathrm{N} 4 / \mathrm{C} 5$, with the largest deviation from this plane not exceeding 0.025 (2) $\AA$. The second half of the ring is composed of atoms $\mathrm{C} 2 / \mathrm{N} 1 / \mathrm{C} 7 / \mathrm{N} 6 / \mathrm{C} 5$ and only atom N6 is displaced from the mean plane, by 0.115 (2) $\AA$; for the other atoms, the deviation does not exceed 0.063 (2) $\AA$. The dihedral angle between the two halves is $64.7(1)^{\circ}$ and is almost in the range of values found for this group of compounds (57.74-63.93 Aubert et al., 2007; Lena et al., 2006; Lena \& Guichard, 2008; Schaffner et al., 2006). The plane of the benzene ring makes angles of 82.1 (1) and $66.9(1)^{\circ}$ with these planes, respectively. Amide atom N4 is almost exactly in the plane defined by the three neighbouring $\mathrm{C}$ atoms $(\mathrm{C} 3, \mathrm{C} 5$ and $\mathrm{C} 11)$, at a distance not exceeding $0.03 \AA$. Therefore, the sum of the valence angles around the $\mathrm{N}$ atom is $359.8(2)^{\circ}$, which identifies very clear $s p^{2}$ hybridization $\left(328^{\circ}\right.$ for $s p^{3}$ and $360^{\circ}$ for $\left.s p^{2}\right)$.

In the crystal structure of (I), molecules are linked by two $\mathrm{C}=\mathrm{O} \cdots \mathrm{H}-\mathrm{N}$ hydrogen bonds (Table 2 and Fig. 2), which consecutively generate the graph-set motif $C_{2}^{1}(6)$ (Bernstein $e t$ $a l ., 1995)$ and form chains of molecules running along the [100] direction. Adjacent molecules in these chains are also doublebridged by the hydrogen bonds, so that an $R_{2}^{2}(8)$ ring motif can additionally be discerned. The planes of parallel benzene rings of neighbouring molecules are separated from each other by $7.01 \AA$. The acetonitrile solvent molecules are in the space between these planes. The distance from the centre of the benzene ring to the nearest $\mathrm{H}$ atom of the methyl group of acetonitrile is about $2.6 \AA$. The third $\mathrm{H}$ atom of this group takes part in a weak $\mathrm{C} 20-\mathrm{H} 20 \mathrm{C} \cdots \mathrm{O} 1$ hydrogen bond (Table 2). Atom N7 of the acetonitrile solvent molecule does not participate in hydrogen bonds, but forms a significant interaction with amide atom N4 (3.36 $\AA$ ), the N7..N4 direction being nearly perpendicular to the amide $s p^{2}$ plane.

\section{Experimental}

The title compound was prepared starting from benzyl bromoacetate. Reaction with veratrylamine gave the corresponding $N$-alkylated aminobenzyl ester in $71 \%$ yield. Coupling with Boc-L-Tic-OH followed by hydrogenolysis afforded the corresponding $\mathrm{N}$-Bocprotected dipeptide in $90 \%$ yield. The dipeptide was then used in a four-step procedure as described previously (Lena et al., 2006), to give the title triazepanedione in $50 \%$ yield. Compound (I) was recrystallized by slow evaporation of a 1:1 mixture of methanol and acetonitrile.

Crystal data

$\mathrm{C}_{16} \mathrm{H}_{23} \mathrm{~N}_{3} \mathrm{O}_{4} \cdot \mathrm{C}_{2} \mathrm{H}_{3} \mathrm{~N}$

$M_{r}=362.41$

Orthorhombic, $P 2_{1} 2_{1} 2_{1}$

$a=7.0090(2) \AA$

$b=10.5040(3) \AA$

$c=25.5620(9) \AA$

$$
\begin{aligned}
& V=1881.9(1) \AA^{3} \\
& Z=4 \\
& \text { Mo } K \alpha \text { radiation } \\
& \mu=0.09 \mathrm{~mm}^{-1} \\
& T=100 \mathrm{~K} \\
& 0.3 \times 0.1 \times 0.1 \mathrm{~mm}
\end{aligned}
$$

\section{Data collection}

Oxford Xcalibur diffractometer

6144 measured reflections

3421 independent reflections

2881 reflections with $I>2 \sigma(I)$ $R_{\text {int }}=0.013$

\section{Refinement}

$R\left[F^{2}>2 \sigma\left(F^{2}\right)\right]=0.036$

$w R(F)=0.027$

$S=1.65$

3421 reflections
235 parameters

$\mathrm{H}$-atom parameters constrained

$\Delta \rho_{\max }=0.05{\mathrm{e} \AA^{-3}}^{-3}$

$\Delta \rho_{\min }=-0.04$ e $\AA^{-3}$
Least-squares refinements, based on $|F|$, were carried out with the program MoPro (Guillot et al., 2001; Jelsch et al., 2005) using the ELMAM electron-density database (Zarychta et al., 2007). According to Wilson (1976), a refinement versus $F$ is equivalent to obtaining a least-squares fit between the calculated electron density and that obtained from a Fourier series based on the observed structure factors. A refinement versus $I$ is equivalent to obtaining a least-squares fit for the Patterson syntheses. Both refinements versus $F$ and $I$ are valid, and are very close for good quality structures. The 
Table 1

Selected geometric parameters $\left(\AA,^{\circ}\right)$.

\begin{tabular}{lclr}
\hline $\mathrm{N} 1-\mathrm{C} 7$ & $1.351(2)$ & $\mathrm{N} 4-\mathrm{C} 5$ & $1.462(2)$ \\
$\mathrm{N} 1-\mathrm{C} 2$ & $1.463(2)$ & $\mathrm{N} 6-\mathrm{C} 7$ & $1.357(2)$ \\
$\mathrm{C} 3-\mathrm{N} 4$ & $1.359(2)$ & & \\
$\mathrm{C} 3-\mathrm{N} 4-\mathrm{C} 11$ & $119.5(1)$ & $\mathrm{C} 5-\mathrm{N} 4-\mathrm{C} 11$ & $119.4(1)$ \\
$\mathrm{C} 3-\mathrm{N} 4-\mathrm{C} 5$ & $120.9(1)$ & & \\
$\mathrm{N} 1-\mathrm{C} 7-\mathrm{N} 6-\mathrm{C} 5$ & $17.1(1)$ & $\mathrm{C} 3-\mathrm{N} 4-\mathrm{C} 5-\mathrm{N} 6$ & $-68.64(9)$ \\
$\mathrm{N} 1-\mathrm{C} 2-\mathrm{C} 3-\mathrm{N} 4$ & $71.15(9)$ & $\mathrm{C} 3-\mathrm{C} 2-\mathrm{N} 1-\mathrm{C} 7$ & $-67.4(1)$ \\
$\mathrm{C} 2-\mathrm{N} 1-\mathrm{C} 7-\mathrm{N} 6$ & $0.5(1)$ & $\mathrm{N} 4-\mathrm{C} 5-\mathrm{N} 6-\mathrm{C} 7$ & $38.6(1)$ \\
$\mathrm{C} 2-\mathrm{C} 3-\mathrm{N} 4-\mathrm{C} 5$ & $4.8(1)$ & & \\
\hline
\end{tabular}

Table 2

Hydrogen-bond geometry $\left(\AA{ }^{\circ}\right)$.

\begin{tabular}{lllll}
\hline$D-\mathrm{H} \cdots A$ & $D-\mathrm{H}$ & $\mathrm{H} \cdots A$ & $D \cdots A$ & $D-\mathrm{H} \cdots A$ \\
\hline $\mathrm{N} 1-\mathrm{H} 1 \cdots \mathrm{O} 2^{\mathrm{i}}$ & 1.01 & 1.79 & $2.792(1)$ & 172 \\
$\mathrm{C} 2-\mathrm{H} 2 \cdots \mathrm{O} 4^{\mathrm{ii}}$ & 1.10 & 2.41 & $3.485(2)$ & 165 \\
$\mathrm{~N} 6-\mathrm{H} 6 \cdots \mathrm{O} 2^{\mathrm{iii}}$ & 1.01 & 1.93 & $2.917(1)$ & 166 \\
\hline
\end{tabular}

Symmetry codes: (i) $x-\frac{1}{2},-y+\frac{1}{2},-z+1$; (ii) $x, y-1, z$; (iii) $x+\frac{1}{2},-y+\frac{1}{2},-z+1$.

diffraction data set had no negative intensity and the refinement versus $|F|$ was carried out using all reflections. The weighted $R$ factor $w R$ and goodness-of-fit $S$ are based on $F$, and conventional $R$ factors are based on $F$. The threshold expression of $F^{2}>2 \sigma\left(F^{2}\right)$ is used only for calculating $R$ factors and is not relevant to the choice of reflections for refinement. The reflection weights were set equal to $7.29 / \sigma^{2}\left(F_{\mathrm{o}}\right)$. The riding was defined with $U_{\text {iso }}(\mathrm{H})=1.5 U_{\mathrm{eq}}(\mathrm{C})$ for methyl groups and $U_{\text {iso }}(\mathrm{H})=1.2 U_{\text {eq }}(X)$ for all other chemical groups. The $\mathrm{H}-X$ distances were constrained to standard values from neutron diffraction studies (Allen, 1986) in the IAM and ELMAM refinements. The target distances were $1.059 \AA$ for $\mathrm{C}-\mathrm{CH}_{3}, 1.066 \AA$ for $\mathrm{O}-\mathrm{CH}_{3}, 1.009 \AA$ for amide $\mathrm{N}-\mathrm{H}, 1.083 \AA$ for aromatic $>\mathrm{C}-\mathrm{H}$, $1.092 \AA$ for $>\mathrm{CH}_{2}$ groups and $1.099 \AA$ for $s p^{3} \mathrm{C}-\mathrm{H}$ groups.

Data collection: CrysAlis CCD (Oxford Diffraction, 2008); cell refinement: CrysAlis RED (Oxford Diffraction, 2008); data reduction: CrysAlis RED; program(s) used to solve structure: SIR92
(Altomare et al., 1994); program(s) used to refine structure: MoPro (Guillot et al., 2001; Jelsch et al., 2005); molecular graphics: SHELXTL (Sheldrick, 2008); software used to prepare material for publication: MoPro.

Supplementary data for this paper are available from the IUCr electronic archives (Reference: GD3337). Services for accessing these data are described at the back of the journal.

\section{References}

Allen, F. H. (1986). Acta Cryst. B42, 515-522.

Altomare, A., Cascarano, G., Giacovazzo, C., Guagliardi, A., Burla, M. C., Polidori, G. \& Camalli, M. (1994). J. Appl. Cryst. $27,435$.

Aubert, E., Lena, G., Gellenoncourt, M., Durain, E., Guichard, G. \& Didierjean, C. (2007). Acta Cryst. E63, o2306-02308.

Bernstein, J., Davis, R. E., Shimoni, L. \& Chang, N.-L. (1995). Angew. Chem. Int. Ed. Engl. 34, 1555-1573.

Boessenkool, I. K. \& Boyens, J. C. A. (1980). J. Cryst. Mol. Struct. 10, 11-18. Guillot, B., Viry, L., Guillot, R., Lecomte, C. \& Jelsch, C. (2001). J. Appl. Cryst. 34, 214-223.

Hempel, A., Camerman, N., Camerman, A. \& Mastropaolo, D. (2005). Acta Cryst. E61, o1313-o1315.

Jelsch, C., Guillot, B., Lagoutte, A. \& Lecomte, C. (2005). J. Appl. Cryst. 38, $38-54$.

Jelsch, C., Pichon-Pesme, V., Lecomte, C. \& Aubry, A. (1998). Acta Cryst. D54, 1306-1318.

Lena, G. \& Guichard, G. (2008). Curr. Org. Chem. 12, 813-835.

Lena, G., Lallemand, E., Gruner, A. C., Boeglin, J., Roussel, S., Schaffner, A.-P., Aubry, A., Franetich, J.-F., Mazier, D., Landau, I., Briand, J.-P., Didierjean, C., Rénia, L. \& Guichard, G. (2006). Chem. Eur. J. 12, 84988512.

Lisgarten, J. N., Palmer, R. A. \& Saldanha, J. W. (1989). Acta Cryst. C45, 656658.

Muller, P., Lena, G., Boilard, E., Bezzine, S., Lambeau, G., Guichard, G. \& Rognan, D. (2006). J. Med. Chem. 49, 6768-6778.

Oxford Diffraction (2008). CrysAlis CCD and CrysAlis RED. Versions 1.171.32.29. Oxford Diffraction Ltd, Yarnton, Oxfordshire, England.

Pichon-Pesme, V., Jelsch, C., Guillot, B. \& Lecomte, C. (2004). Acta Cryst. A60, 204-208.

Schaffner, A.-P., Lena, G., Roussel, S., Wawrezinieck, A., Aubry, A., Briand, J.-P., Didierjean, C. \& Guichard, G. (2006). Chem. Commun. pp. 4069-4071. Sheldrick, G. M. (2008). Acta Cryst. A64, 112-122.

Wilson, A. J. C. (1976). Acta Cryst. A32, 781-783.

Zarychta, B., Pichon-Pesme, V., Guillot, B., Lecomte, C. \& Jelsch, C. (2007). Acta Cryst. A63, 108-125. 